\title{
Mineral nutrition of the pig
}

\section{By I. G. PARTridge, National Institute for Research in Dairying, Shinfield, Reading RG2 $9 A T$}

This paper discusses the difficulties in determining the mineral requirements of pigs. The problems involved are closely linked with the complexities of mineral absorption and metabolism. Recent research aimed at elucidating these processes is reviewed. Space does not permit a comprehensive discussion of all the essential mineral nutrients so calcium and phosphorus are used as examples since these have received the most attention.

One of the most difficult problems facing pig nutritionists is to establish accurately the appropriate amounts of essential mineral nutrients which should be included in the diets for different classes of pig. In 1967 the Working Party of the Agricultural Research Council stated that experiments on the mineral needs of pigs, though extensive, were far from comprehensive (Agricultural Research Council, 1967). The recent review by Mudd \& Stranks (1979) indicates that the same is true today, despite the large number of trials reported in the intervening I 2 years. All aspects of mineral nutrition are associated with controversy and conflicting evidence. It is very difficult to rationalize the evidence to obtain an estimate of the requirement for a particular element without confounding the very important animal, dietary and environmental factors which vary widely between experiments. To give an example, the suggested $\mathrm{Ca}$ requirement of young pigs is $8.0 \mathrm{~g} / \mathrm{kg}$ dry matter (DM) but individual estimates of the requirement range from 2.0 to $13.0 \mathrm{~g} / \mathrm{kg}$ DM (Agricultural Research Council, 1967). Estimates for other elements vary to a similar extent.

Clearly there is room for improving precision but it is important to consider what extent of accuracy is desirable in estimating mineral requirements. It may be argued that rough approximations are adequate since mineral supplements are relatively cheap and extra allowances can be added to the diet. At present it costs approximately $f_{2} / \mathrm{t}$ to supplement a cereal-soya-bean-meal diet with minerals according to Agricultural Research Council (r 967 ) recommendations. Of this, approximately $f_{I}$ is the cost of $P$ supplementation. With diets costing upwards of $f_{1} 120 / t$, mineral costs are a minor consideration at present but there are indications that phosphates in particular will become increasingly scarce and expensive. The addition of excessive amounts of minerals is undesirable for other reasons. First, imbalances may result, causing impaired performance. It is well known, for example, that high levels of $\mathrm{Ca}$ can interfere with zinc metabolism. Increasing $\mathrm{Ca}$ level from as low as $6.4 \mathrm{~g} / \mathrm{kg}$ DM has been shown to increase urinary excretion of $\mathrm{Zn}$ (Newland et al. 1958) and a level of $12.0 \mathrm{~g} / \mathrm{kg}$ can depress $\mathrm{Zn}$ absorption (Berry et al. 196I). Furthermore, it is important to remember that feeding excess 
minerals increases the output in slurry. Even if this does not pose a real threat to the environment, recent difficulties concerning the supplementation of pig diets with copper suggest that the suspicion that it might do so could lead to restrictive EEC legislation.

Two methods have been used to assess the mineral requirements of pigs. These are generally known as the empirical method and the factorial method. Recommendations are usually based on the composite evidence obtained by the two approaches.

\section{Empirical observations}

Much information on mineral requirements has been amassed from trials in which different levels of an element have been fed in order to determine the level which satisfies some criterion or criteria of adequacy. There are dangers in attempting to determine from the results an average requirement which is generally applicable. Even where there is sufficient information to indicate averages for different live-weight classes of pigs, different experimental conditions give quite different results. Furthermore, a single value is of doubtful use given the diverse feeds, feeding systems and management systems prevailing throughout the pig-keeping industry.

A more important question concerns the selection of appropriate criteria for assessing adequacy. In the past the usual yardsticks have been health, daily gain and feed:gain ratio. It is questionable whether these are adequate for all elements. In relation to $\mathrm{Ca}$ and $\mathrm{P}$ requirements it has become increasingly common to consider bone factors such as mineral content and breaking strength. The dietary requirements for these elements is considerably higher if maximum bone mineralization or maximum breaking strength is the criterion, rather than maximum daily gain. But is it necessary to maximize these bone factors?

The diverse experimental conditions and factors measured have led to a very wide range in estimates of requirements. To consider a few of the reports on $\mathrm{Ca}$ requirement of $20-90 \mathrm{~kg}$ pigs which have appeared since the publication of the Agricultural Research Council ( 1967 ) recommendations, a number of authors have found that a dietary $\mathrm{Ca}$ level of approximately $3.5 \mathrm{~g} / \mathrm{kg}$ is adequate to support maximum growth rate (e.g. Libal et al. 1969; Mudd et al. 1969; Cromwell et al. 1972). However, growth responses to higher levels have been reported. For example, Reinhard et al. (1976) found that $9.0 \mathrm{~g} / \mathrm{kg}$ gave faster growth than $6.5 \mathrm{~g} / \mathrm{kg}$ in pigs given a high-protein diet. For maximum bone mineralization dietary Ca levels of approximately $10 \mathrm{~g} / \mathrm{kg}$ have been generally suggested (e.g. Vemmer et al. 1973; Reinhard et al. 1976) although other trials have indicated that levels as low as $6 \mathrm{~g} / \mathrm{kg}$ are adequate (e.g. Stockland \& Blaylock, 1973). It is possible that different conclusions may be drawn depending on the sample bone chosen for study: Schroeder et al. (1974) found that for maximum bone breaking strength the required dietary Ca level was $12 \mathrm{~g} / \mathrm{kg}$ for the femur but only $7.5 \mathrm{~g} / \mathrm{kg}$ for a metacarpal. The higher levels of $\mathrm{Ca}$ apparently required for optimum bone development conflict with evidence that higher levels may depress growth rate. In 


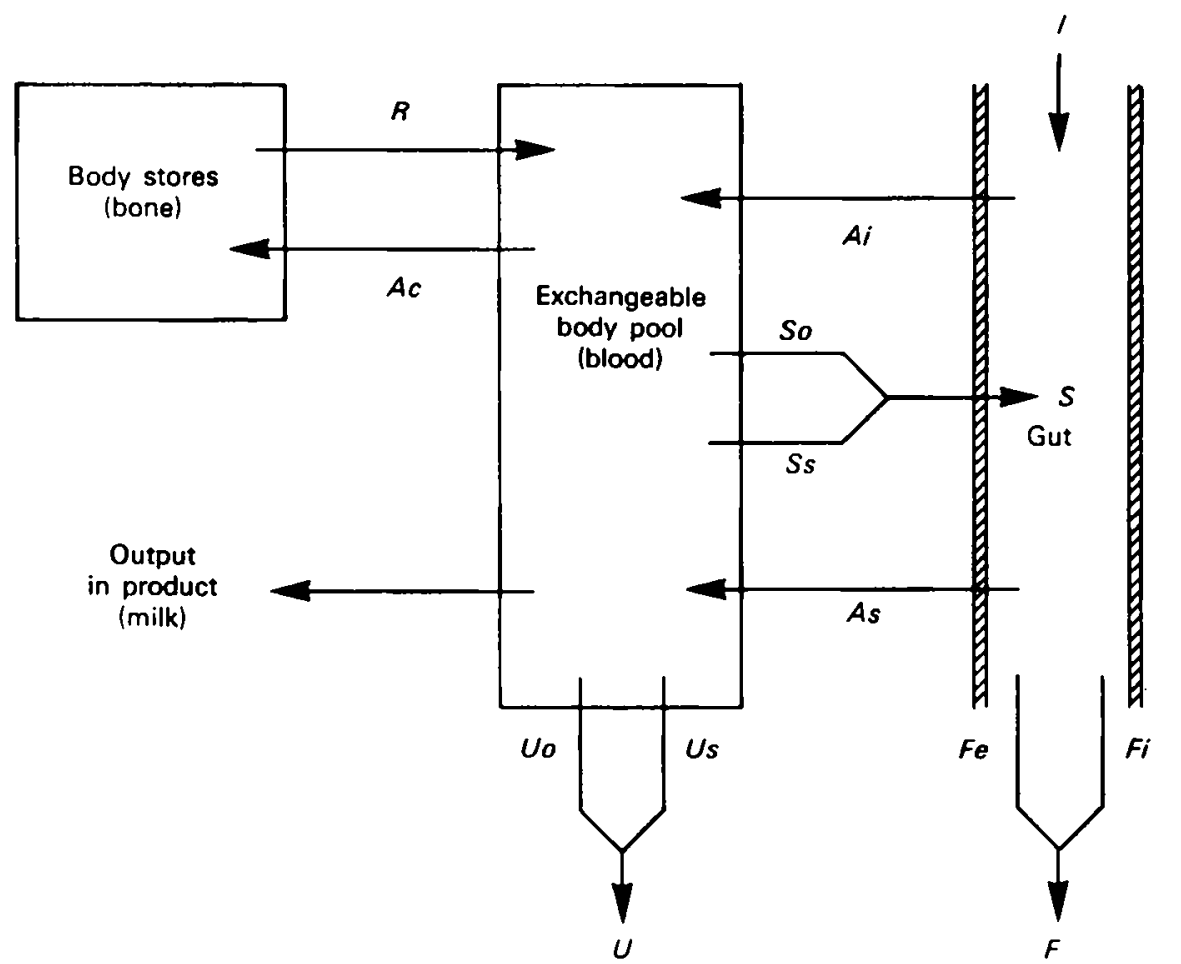

Fig. 1. Generalized diagrammatic representation of mineral metabolism. I, element intake; $F$, total element in faeces; $F i$, unabsorbed dietary element in faeces; $F e$, endogenous or secreted but not reabsorbed element in faeces; $A i$, absorbed dietary element; $A s$, reabsorption of secreted element; $S$, total element secreted into gut; So, obligatory secretion of element; $S s$, secretion of element surplus to requirement; $U$, total element in urine; $U o$, obligatory loss in urine; $U s$, urinary excretion of element surplus to requirement; $A c$, accretion of element; $R$, resorption of element.

some experiments with $20-90 \mathrm{~kg}$ pigs a dietary level of only $7.5 \mathrm{~g} / \mathrm{kg}$ was too high (Frolich \& Thomke, 1968; Cromwell et al. 1970).

\section{Factorial calculation of requirements}

The dietary requirement for a mineral element can be expressed as an equation relating the factors involved in its absorption and metabolism. A simplified diagram illustrating the main aspects of mineral metabolism is given in Fig. I. The animal's net requirement for an element is the sum of storage in the body, product loss (milk) and obligatory endogenous losses in faeces and urine (plus any losses in skin and hair). The amount of the element which must be included in the diet to ensure that the net requirement is met is related to the net requirement by the availability of the element. Thus:

Dietary requirement for a mineral $=\frac{\text { net mineral requirement }}{\text { mineral availability }}$ 
The danger in simplifying requirements in this way is that the expression implies a constant relationship. A great deal of confusion surrounds the use of the terms net requirement and availability and too often it is mistakenly implied that they are constants, irrespective of the conditions under which they are measured.

Net mineral requirement. The storage with growth or retention of an element can be measured by carcase analysis and by mineral balance experiments. The two methods do not always give good agreement. For example, Just Nielsen (1972) found that carcases of pigs contained $15 \%$ less $\mathrm{Ca}$ and $39 \%$ less $\mathrm{P}$ than was indicated by balance studies conducted during the growth of the same animals. In addition to errors of measurement it should be remembered that the amount of an element retained depends to some extent on the amount ingested. In the instance of $\mathrm{Ca}$ this is implicit in the empirical evidence on bone mineralization discussed previously, and has also been clearly demonstrated in young pigs by Blair \& Benzie (1964). This means that in order to use the factorial method to determine requirements accurately it is necessary to define what constitutes an appropriate level of retention of each element. At present this can only be done by arbitrary assessment.

The other major component of the growing pig's net requirement for an element is the obligatory endogenous loss. As shown in Fig. 1 the endogenous losses in faeces $(\mathrm{Fe})$ and in urine $(U)$ each have two components. Faecal endogenous loss $(F e)$ consists of element secreted into the gut $(S)$ and not reabsorbed. Part of this is obligatory loss $(S o)$ and part $(S s)$ represents the excretion of element surplus to body requirements. Similarly, urinary loss $(U)$ can consist of an obligatory component (Uo) and a surplus component $(U s)$. The relative importance of the two excretory routes varies for different elements depending on the sites of action of the homoeostatic control mechanisms.

Urinary excretion can be measured directly and faecal endogenous loss can be measured by radioisotope procedures but it is not possible to distinguish between the obligatory and surplus components of either. The obligatory loss of $\mathrm{Ca}$ has been estimated by regression of retention $v$. intake and extrapolation to zero intake (e.g. Thorbek, 1960; Mudd et al. 1969).

I would like to consider an alternative approach to the determination of net mineral requirements. This might form the basis of a practicable method, but it is presented more as a means of illustrating the principles involved.

It should be possible to determine the net requirement for an element by including a range of levels of a soluble salt in a purified diet and determining the level of intake at which homoeostatic mechanisms begin to operate to limit accumulation of the element in the body. At intake levels which are insufficient to satisfy the net requirement, excretion of the element in urine and faeces should be at a minimum and equal to the obligatory losses, $S o$ and $U o$ in Fig. I. This assumes that the true digestibility of the element is $\mathrm{I} \cdot 00$ in these circumstances. This was the situation for $\mathrm{Ca}$ and $\mathrm{P}$ absorption in a study on rats reported by Whittemore et al. (1973) and for $\mathrm{Ca}$ absorption in a study on pigs reported by Mudd et al. (1969). When intake exceeds the point at which the net requirement is 
met, total excretion of the element in urine plus faeces will increase. This may be achieved in a number of ways: absorption $(A i, A s)$ may decrease, faecal endogenous secretion $(S)$ may increase due to the $S s$ component and urinary excretion may increase due to the Us component.

This procedure would in effect allow the homoeostatic mechanisms of the pig to dictate the appropriate level of mineral retention. Whether this would correspond with the nutritionists view of optimum retention would have to be tested experimentally but at least it is an objective assessment. There is evidence to show that $\mathrm{Ca}$ retention does continue to increase with increasing intake while efficiency of retention decreases (e.g. Mudd et al. 1969). In applying the procedure it would be important as with all mineral studies to take into account interactions between elements.

Mineral availability. The difficulties associated with the concept of availability have been discussed by Thompson (1965). First there is confusion in terminology. Terms such as availability (true and apparent), utilization, digestibility (true and apparent), absorption and retention continue to be used synonymously or given different definitions by different authors. Secondly, there are two overlapping but different concepts of availability. Some consider availability to be a characteristic of a particular source of an element. Others consider it to be a measure of the metabolic state of the animal. In fact both aspects are important. In estimating mineral requirements factorially it must be remembered that on the one hand the proportion of an element that can be extracted by digestion and absorption differs from one source to another; on the other hand the amount that is absorbed and utilized depends on the metabolic demands of the animal. It follows from the latter that availability will be reduced as intake increases above the required level for elements whose absorption is regulated homoeostatically. A clear example of this is given by Whittemore et al. (1973) who found that in rats given purified diets $\mathrm{Ca}$ availability, measured by three different radioisotope procedures, decreased from approximately $\mathrm{I} .00$ at low intakes to approximately 0.28 at a high intake.

In view of the these considerations, availability is best defined as that proportion of a stated amount of an element ingested in a given source or diet which is absorbed and utilized by the animal to meet its net requirement.

In the hypothetical method for measuring net requirement discussed previously, availability as a characteristic of the dietary source is excluded from the argument by considering only a source which could be completely absorbed and utilized to meet the metabolic demand. However, the availability of the source is a very important factor in the formulation of practical pig diets. It has been a common practice to measure the availability of a mineral element in mixed diets containing inorganic supplements, often providing a total dietary level of the element in excess of the supposed requirement. This is misleading due to the confounding of the two aspects of availability described previously. The value determined in this way tends to underestimate the potential of the source or sources since absorption is restricted homoeostatically, for some elements at least. A more logical way to evaluate a source or mixed sources is to measure availability from the 
unsupplemented ingredients, which will give a maximum value. This, together with a knowledge of the net requirement, will allow the appropriate level of supplementation to be calculated.

\section{Absorption and metabolism of $\mathrm{Ca}$ and $\mathrm{P}$}

It is clearly very difficult to separate the practical aspects of mineral nutrition from the underlying processes of absorption and metabolism. In recent years considerable progress has been made in understanding these processes, particularly concerning $\mathrm{Ca}$ and $\mathrm{P}$. While much of this work has been done with small laboratory animals, I will briefly review some of the work in pigs.

Besancon \& Gueguen ( 1969 ) prepared a model describing quantitatively the principal aspects of $\mathrm{Ca}$ metabolism in growing pigs, based on studies with ${ }^{45} \mathrm{Ca}$. Their results were interpreted according to the compartmental models of Aubert \& Milhaud (1960) and Bauer et al. (1961). Although the values obtained in studies of this kind are specific to the conditions of the experiment, this provides a useful picture of the processes involved. Under their conditions, in pigs of $30-40 \mathrm{~kg}$ growing at $300-600 \mathrm{~g} / \mathrm{d}$ and receiving $11.6 \mathrm{~g} \mathrm{Ca} / \mathrm{d}$, Besancon \& Gueguen (1969) found that true absorption of $\mathrm{Ca}$ was 0.45 of that ingested; 0.17 of total faecal $\mathrm{Ca}$ was of endogenous origin; $3.4 \mathrm{~g} \mathrm{Ca} / \mathrm{d}$ was retained. Total accretion of $\mathrm{Ca}$ (bone anabolism) was calculated to be $10.7 \mathrm{~g} / \mathrm{d}$ and resorption (bone catabolism) was, therefore, $7.3 \mathrm{~g} / \mathrm{d}$. Of the total accretion, 0.46 was of endogenous origin due to recycling of bone $\mathrm{Ca}$, indicating the capacity of bone to renew itself. The total exchangeable $\mathrm{Ca}$ pool was estimated to be $24 \mathrm{~g}$. Similar models for other elements would be of considerable value but the metabolism of most elements is more complex than that of $\mathrm{Ca}$. Of the total body $\mathrm{Ca} 0.99$ is deposited in bone but other elements have more diverse metabolic functions.

Chronic cannulation of the intestine has been used to study sites of absorption and secretion of mineral elements and the effects of diet composition. Thiry-Vella loops of intestine have been used to study the mechanisms of $\mathrm{Ca}$ and $\mathrm{P}$ absorption and their control in pigs. These absorption studies have recently been reviewed by Partridge (I980).

The absorptions of $\mathrm{Ca}$ and $\mathrm{P}$ (amongst other elements) were measured in growing pigs fitted with single re-entrant cannulas in the duodenum, mid-jejunum or terminal ileum, and over-all absorption was measured in non-cannulated pigs by Partridge (1978a). The mean live weight of the pigs was $40 \mathrm{~kg}$. The diets compared were based on barley, weatings and fish meal (diet BWF) or starch, sucrose and casein (diet SSC). It was shown that the small intestine was the main site of $\mathrm{Ca}$ and $\mathrm{P}$ absorption but there were differences between diets in the relative importance of the regions anterior and posterior to the mid-jejunum. With the cereal diet (diet BWF) the proximal region of the small intestine was the more important. This confirms the results of studies with slaughtered pigs using ${ }^{45} \mathrm{Ca}$ and ${ }^{32} \mathrm{P}$ reported by Moore \& Tyler (1955). It is also in accordance with observations on the location of intestinal Ca-binding protein in the pig (Fulmer \& Wasserman, 1975; Harrison et al. 1975; Fox et al. 1977). 
In studies with pigs fitted with ileal re-entrant cannulas Partridge (1978b) showed that dietary fibre level may have important effects on the absorption of $\mathrm{Ca}$ and $P$. The pigs were given semi-purified diets containing cellulose at either 30 or $90 \mathrm{~g} / \mathrm{kg}$. For the low-cellulose diets the apparent absorption (faeces measurements) for $\mathrm{Ca}$ and $\mathrm{P}$ was 0.74 and 0.81 respectively; corresponding values for the highcellulose diet were significantly lower at 0.63 and 0.74 respectively. Ileal digesta measurements showed that the difference was entirely due to reduced absorption of these elements from the large intestine. Other elements were similarly affected. Reduced mineral absorption due to dietary fibre has been observed in other species. This could have practical relevance in the use of bulky feeds for pigs.

$\mathrm{Ca}$ metabolism is chiefly regulated by parathyroid hormone (PTH), calcitonin (CT) and derivatives of cholecalciferol. Swaminathan et al. (1974) showed that CT is important in the pig's adaptation to a high- $\mathrm{Ca}$ diet. Intravenous infusion of the hormone reduced the absorption of ${ }^{47} \mathrm{Ca}$ from jejunal loops. A 2-4 d time-lag in the response was suggested to be the time taken to reduce mucosal Ca-binding protein. The inclusion of hydroxylated derivatives of cholecalciferol in the perfusate enhanced the absorption of $\mathrm{Ca}$ and $\mathrm{P}$ from jejunal loops in work reported by Fox \& Care (1976). Again there was a delay before the peak response was observed, probably due to the time taken for synthesis of Ca-binding protein. Fox et al. (1977) found that the efficiency of net absorption of $\mathrm{Ca}$ from isolated jejunal loops was increased in response to a decrease in dietary Ca level from 12 to $\mathrm{I} g / \mathrm{kg}$ in both intact and parathyroidectomized pigs. However, this dietary change reduced the mucosal content of Ca-binding protein only in intact animals. This showed that enhanced absorption in response to a low-Ca diet is not dependent on PTH and does not necessarily involve Ca-binding protein.

Fox et al. (1978) have also studied the effects of altering the concentrations of $\mathrm{Ca}$ and $\mathrm{P}$ in the perfusate on their absorption from Thiry-Vella loops of jejunum. For $\mathrm{Ca}$, as the concentration increased at low levels absorption rate increased rapidly whereas at higher levels the increase in absorption rate was much slower. The two phases of absorption probably correspond to active absorption against a concentration gradient at low luminal concentrations and passive absorption at higher concentrations. Absorption of $\mathrm{P}$ does not follow the same biphasic pattern: as $\mathrm{P}$ concentration in the perfusate increased, $\mathrm{P}$ absorption increased but at a decreasing rate. The absorption of $\mathrm{Ca}$ was unaffected by the presence of $\mathrm{P}$ but $\mathrm{Ca}$ enhanced the absorption of $P$.

Some interesting studies on the kinetics of $\mathrm{P}$ absorption in pigs have been reported by Gueguen and associates (Gueguen \& Rerat, 1967; Gueguen et al. 1968; Gueguen et al. 1970). By studying the variations in plasma radioactivity after giving ${ }^{32} \mathrm{P}$ intravenously or orally Gueguen \& Rerat (1967) showed that absorption of $P$ given as disodium phosphate commenced $10-15$ min after the animals started to eat. Absorption of soluble $\mathbf{P}$ was exponential during the first $2 \mathrm{~h}$ : half was absorbed during the first $30 \mathrm{~min}$ after feeding. Gueguen et al. (1968) compared the absorption of ${ }^{32} \mathrm{P}$ given either as disodium phosphate or as activated wheat bran. True digestibility was 0.71 for the former and 0.37 for the latter. The 
efficiency of retention of absorbed $\mathrm{P}$ was lower for wheat bran than for disodium phosphate. It was thought that this was due to the longer time taken to digest and absorb the phytate-P of wheat bran. A hypothesis was proposed suggesting that the simultaneous absorption of $\mathrm{Ca}$ and $\mathrm{P}$ would favour their maximum retention. Further evidence for this was provided by Gueguen et al. (1970) who showed that when ${ }^{32} \mathrm{P}$ alone was infused intravenously, pigs retained 0.64 of the dose. When ${ }^{32} \mathrm{P}$ and $\mathrm{Ca}$ were infused together retention of ${ }^{32} \mathrm{P}$ was increased to 0.80 of the dose.

It seems that in the next few years basic studies of mineral absorption and metabolism should lead to a better understanding of these processes. This in turn should allow a more rational approach to the determination of mineral requirements.

\section{REFERENCES}

Agricultural Research Council (1967). In The Nutrient Requirements of Farm Livestock No. 3, Pigs. London: HM Stationery Office.

Aubert, J. P. \& Milhaud, G. (1960). Biochim. biophys. Acta 39, 122.

Bauer, G. C. H., Carlsson, A. \& Lindquist, B. (196I). In Mineral Metabolism, vol. IB p. 609.

[C. L. Comar and F. Bronner, editors]. New York: Academic Press.

Berry, R. K., Bell, M. C., Grainger, R. B. and Buescher, R. G. (1961). F. Anim. Sci. 20, 433. Besancon, P. \& Gueguen, L. (1969). Annls Biol. anim. Biochim. Biophys. 9, 537.

Blair, R. \& Benzie, D. (1964). Br. F. Nutr. 18, gr.

Cromwell, G. L., Hays, V. W., Chaney, C. H. \& Overfield, J. R. (1970). J. Anim. Sci. 30, 519.

Cromwell, G. L., Hays, V. W. \& Kratzer, D. D. (1972). f. Anim. Sci. 35, 215.

Fox, J., Care, A. D. \& Swaminathan, R. (1978). Br. J. Nutr. 39, 43 I.

Fox, J. \& Care, J. (1976). Calc. Tiss. 21, Suppl. 147.

Fox, J., Swaminathan, R., Murray, T. M. \& Care, A. D. (1977). f. Endocr. 74, 345.

Frolich, A. \& Thomke, S. (1968). LantBr. Hogsk. Meddn. Ser. A, no. 98, p. 45.

Fulmer, C. S. \& Wasserman, R. H. (1975). Biochim. biophys. Acta 393, I34.

Gueguen, L., Besancon, P. \& Rerat, A. A. (1968). Annls Biol. anim. Biochim. Biophys. 8, 273.

Gueguen, L., Besancon, P. \& Rerat, A. A. (1970). C.r. hebd. Seanc. Acad. Sci., Ser. D, Paris 270,2678 .

Gueguen, L. \& Rerat, A. A. (1967). Annls Biol. anim. Biochim. Biophys. 7, 39.

Harrison, J. E., Hitchman, A. J. W. \& Brown, R. G. (1975). Can. F. Physiol. Pharmac. 53, 144. Just Nielsen, A. (1972). Acta Agric. scand. 22, 223.

Libal, G. W., Peo, E. R., Andrews, R. P. \& Vipperman, P. E. (1969). F. Anim. Sci. 28, 331. Moore, J. H. \& Tyler, C. (1955). Br. F. Nutr. 9, 8r.

Mudd, A. J., Smith, W. C. \& Armstrong, D. G. (1969). F. agric. Sci., Camb. 73, I89.

Mudd, A. J. \& Stranks, M. H. (1979). Proc. 3oth A. Mtg Eur. Ass. Anim. Prod., Harrogate.

Newland, H. W., Ullirey, D. E., Hoefer, J. A. \& Luecke, R. W. (1958). F. Anim. Sci. 17, 886.

Partridge, I. G. (1978a). Br. F. Nutr. 39, 527.

Partridge, I. G. (1978b). Br. F. Nutr. 39, 539.

Partridge, I. G. (1 980 ). In Current Concepts of Digestion and Absorption in Pigs. [A. G. Low and I. G. Partridge, editors]. Reading: National Institute of Research in Dairying.

Reinhard, M. K., Mahan, D. C., Workman, B. L., Cline, J. H., Fetter, A. W. \& Grifo, A. P. (1976). F. Anim. Sci. 43, 770 .

Schroeder, J., Tanksley, T. D. \& Ashton, G. C. (1974). F. Anim. Sci. 39, 189.

Stockland, W. L. \& Blaylock, L. G. (1973). f. Anim. Sci. 37, 906.

Swaminathan, R., Ker, J. \& Care, A. D. (1974). F. Endocr. 6r, 83 .

Thompson, A. (1965). Proc. Nutr. Soc. 24, 81.

Thorbek, G. (1960). In Potassium in the Animal Organism. [International Potash Institute, editors]. Berne: International Potash Institute.

Vemmer, H., Oslage, H. J. \& Weiss, F. K. (I973). Landwirt, Forsch. 26, 270.

Whittemore, C. T., Thompson, A. \& Atherton, D. (1973). Br. F. Nutr. 30, 425. 